\title{
Derecho penal y criminología sociológica: integración y desintegración ${ }^{1}$
}

Criminal law and sociological criminology: integration and disintegration

Direito penal e criminologia sociológica: integração e desintegração

Droit pénal et criminologie sociologique: intégration et désintégration

刑法与社会学犯罪学:整合与瓦解

\author{
E. Raúl Zaffaroni ${ }^{2}$
}

Universidad de Buenos Aires - Argentina

Revista Derechos en Acción ISSN 2525-1678/ e-ISSN 2525-1686

Año 5/No 16 Invierno 2020 (21 junio a 20 septiembre), 25-58

DOl: https://doi.org/10.24215/25251678e415

Recibido: 01/08/2020

Aprobado: 01/09/2020

1 Las notas del presente artículo son en su mayoría explicativas, con pocas indicaciones bibliográficas. Una bibliografía completa excedería el marco de unas breves páginas y obligaría a reiterar la que indicamos en diferentes obras. En particular, se hallará en las siguientes, a las que en este sentido remitimos: Tratado de Derecho Penal, Parte General, tomo II, EDIAR, Buenos Aires, 1980-1983; En busca de las penas perdidas. Deslegitimación y dogmática jurídico-penal, EDIAR, Buenos Aires, 1989; Derecho Penal. Parte General (con Alejandro Alagia y Alejandro Slokar), EDIAR, Bs. As., 2002; Crímenes de masa, Ediciones Madres de Plaza de Mayo, Buenos Aires, 2010; La palabra de los muertos. Conferencias de Criminología cautelar, EDIAR, Buenos Aires, 2011; Doctrina Penal Nazi. La dogmática penal alemana entre 1933 y 1945, Tirant lo Blanch, Valencia, 2017; Friedrich Spee: el padre de la criminología crítica, estudio preliminar a la "Cautio Criminalis", EDIAR, Buenos Aires, 2017; La nueva crítica criminológica. Criminología en tiempos de totalitarismo financiero (con Ílison Dias dos Santos), EDIAR, Buenos Aires, 2019.

2 Profesor Emérito de la Universidad de Buenos Aires. 
Resumen: El derecho penal tiene en sí un proyecto de jurisprudencia orientado a construir elementos para la decisión judicial, pero las distintas imágenes y concepciones de la finalidad y funciones del castigo (presentes en la "teoría de la pena") constitutivas de una anomalía en la ciencia jurídica. Desde que concluyó el mundo bipolar la teoría social vigente hasta ese momento, ha quedado con poca utilidad a causa de una nueva fase superior del poder planetario: el "totalitarismo financiero" que avanzó sobre el poder político asumiendo formas de macrociminalidad y profundizando la selectividad punitiva de los sectores vulnerables, con una preocupante plurifuncionalidad amplificante. En este contexto resulta necesaria una nueva crítica sociológica y criminológica al actual marco de poder. La ciencia penal debe retomar el onticismo representado en el saber juridico penal por las estructuras óntico objetivas welzelianas, a fin de salir del idealismo que ha producido un resquebrajamiento entre el "ser" y el "deber ser", y captar la esencia mutable del poder que se debe limitar a través de los datos de la realidad.

Palabras clave: Derecho Penal, Poder Punitivo, Nueva Criminología Crítica, Totalitarismo Financiero, Criminología Sociológica.

Abstract: Criminal law itself has a jurisprudence project aimed at constructing elements for judicial decision, but the different representations and conceptions of the purpose and functions of punishment (present in the "theory of punishment") establish an anomaly in legal science. Since the end of the bipolar world, the social theory in force until that moment has been of little use because of a new phase of planetary power: "financial totalitarianism" that advanced on political power assuming forms of macro-criminality and deepening punitive selectivity of vulnerable sectors, with a worryingly amplifying multi-functionality. In this context, a new sociological and criminological review of the current framework of power is necessary. Criminal science must return to the onticism represented in criminal legal knowledge by Welzelian objective ontic structures, in order to get out of the idealism that has produced a breakdown between "being" and "should be", in view of the mutable essence of power that must be limited through the data of reality.

Keywords: Criminal Law, Punitive Power, New Criminology, Financial Totalitarianism, Sociological Criminology. 
Resumo: 0 próprio direito penal possui um projeto de jurisprudência que visa construir elementos para a decisão judicial, mas as diferentes imagens e concepções sobre a finalidade e as funções da pena (presentes na "teoria da pena") constituem uma anomalia em ciência jurídica. Desde o fim do mundo bipolar, a teoria social vigente até aquele momento tem sido de pouco uso por causa de uma nova fase superior do poder planetário: o "totalitarismo financeiro" que avançou no poder político assumindo formas de macrociminalidade e aprofundando a seletividade punitiva setores vulneráveis, com uma multifuncionalidade preocupantemente amplificadora. Nesse contexto, uma nova crítica sociológica e criminológica ao quadro atual de poder é necessária. A ciência criminal deve retornar ao onticismo representado no conhecimento jurídico penal pelas estruturas ônticas objetivas Welzelianas, para sair do idealismo que produziu uma ruptura entre o "ser" e 0 "deveria ser", e apreender a essência mutável do poder. que deve ser limitado pelos dados da realidade.

Palavras-chave: Direito Penal, Poder punitivo, Nova Criminologia Crítica, Totalitarismo Financeiro, Criminologia Sociológica

Résumé: Le droit pénal lui-même a un projet de jurisprudence visant à construire des éléments de décision judiciaire, mais les différentes images et conceptions du but et des fonctions de la peine (présentes dans la «théorie de la punition») constituent une anomalie dans science juridique. Depuis la fin du monde bipolaire, la théorie sociale en vigueur jusqu'à ce moment a été peu utile en raison d'une nouvelle phase supérieure du pouvoir planétaire: le «totalitarisme financier» qui a avancé sur le pouvoir politique en assumant des formes de macro-criminalité et en approfondissant la sélectivité punitive de secteurs vulnérables, avec une multifonctionnalité qui s'amplifie de manière inquiétante. Dans ce contexte, une nouvelle critique sociologique et criminologique de la situation actuel du pouvoir est nécessaire. La science criminelle doit revenir à l'onticisme représenté dans la connaissance juridique criminelle par les structures ontiques objectives welzeliennes, afin de sortir de l'idéalisme qui a produit une rupture entre "être» et "devrait être», et saisir l'essence mutable du pouvoir cela doit être limité par les données de la réalité.

Mot-clés: droit pénal, pouvoir punitif, nouvelle criminologie critique, totalitarisme financier, criminologie sociologique. 
摘要: 司法, 司法和司法的司法解释, 终审法院和刑事诉公法院的宪 法解释 (代表 “墨西哥教廷”的宪法) 朱里迪卡. 在两极社会中进行紧 急活动的人，必须在一个新的理由中使用上一个星球: 在 “总金融” 中, 要在政治上进行选择.易受伤害的弱势群体, 包括先发制人. 从 实际的角度来看，实际的犯罪事实和犯罪事实之间的必然联系. 法 西斯半岛刑法改革与刑事司法组织, 理想主义政治经济学的最终 产物, “塞维利亚” 和“穆德伯塞尔”被重新封印, 卡普尔一德拉佩 尔西亚魁北克德贝斯限流城. 在这种情况下, 有必要对当前权力框 架进行新的社会学和犯罪学批评. 犯罪学尘须以客观的本体结构“ welzelianas” (韦尔泽) 重新获得以刑事法律知识为代表的本体论, 以便摆脱造成“存在”与 “应当”之间破裂的理想主义, 并抓住可变的 本质必须通过现实的数据来限制的力量.

关键字: 刑法, 惩罚性权力, 新批判犯罪学, 金融极权主义, 社会学犯罪学

\section{La ciencia penal como anomalía jurídica}

En general, cada rama del derecho reconoce las funciones de sus respectivas sanciones, sin mayores disidencias entre sus cultores, que pueden disentir sobre su buen o mal uso, pero no sobre la naturaleza y función de ellas.

Pero entre los penalistas no existe acuerdo al respecto. Ninguna otra materia jurídica ostenta un abanico de opiniones respecto de la función de su sanción similar a nuestro cuadro de teorías de la pena ${ }^{3}$, por lo que es tiempo de reconocer que se trata de una anomalía jurídica.

Sabemos que el ejercicio del poder punitivo sirve para algo y -si dejamos de lado los libros- intuimos sus muy diferentes y múltiples consecuencias, imposibles de reconocer en totalidad. A veces es posible percibir que, en ciertos conflictos, desempeña alguna de las funciones teorizadas en el cuadro de teorías de la pena, pero en otros sería absurdo asignarle el mismo cometido.

3 El cuadro que se reitera con ligeras variantes hasta el presente, fue expuesto en 1830 por Anton Bauer, La teoría de la advertencia y una exposición y evaluación de todas las teorías del Derecho Penal, EDIAR, Buenos Aires, 2019. 
Por eso, cada penalista parte de cómo cree que debiera ser la función y el objeto o fin de la pena y, según esa elección subjetiva, justifica y legitima cierta medida de ejercicio del poder punitivo. Cada penalista dice: la pena debería cumplir esta función y, por ende, la legitimo en la medida en que la cumpla y construyo mi teoría jurídica (sistema) a partir de esta premisa.

Así, según lo que cada uno crea a este respecto, puede elaborar una doctrina penal que legitime al poder punitivo casi ilimitadamente (penalistas horripilantes), que lo limite en gran medida (penalistas garantistas) o que deambule por puntos intermedios (penalistas indecisos). Quien se atreva a entrar en esa selva será desconcertado por una eterna discusión entre los tres, con frecuencia vehemente y agresiva.

El drama de la ciencia jurídico penal es que sus sistemas interpretativos de la ley no son un art pour l'art, puesto que se dirigen a los operadores jurídicos, aspirando a que éstos los conviertan en sentencias que habiliten poder punitivo, que no se ejerce en la sociedad en la forma que cada penalista imagina que debiera ser, sino en la que muestran los datos sociales, cumpliendo funciones que muchas veces ni sospechamos. De cualquier forma, la ciencia jurídico penal no deja de cumplir su función práctica, surte efectos sobre los operadores jurídicos y, entre ellos, los de buena fe se desconciertan, en tanto que los de mala fe escogen el sistema que más conviene para manipular la habilitación del poder punitivo en forma arbitraria.

Para colmo, la criminología mediática ${ }^{4}$, mediante su creación de realidad falsa pero única en la región ${ }^{5}$, expande insólitamente una función que en algunos casos cumple el poder punitivo: la canalización de venganza ${ }^{6}$.

\footnotetext{
4 Sobre este concepto, nuestro libro. La palabra de los muertos, EDIAR, Bs. As., 2011, pp. 365 y ss.

5 En toda la región la ciudadanía es manipulada por monopolios mediáticos en consonancia con el actual totalitarismo financiero transnacional, que suplantan funcionalmente a los partidos políticos, desempeñándose como partitos únicos.

6 Sobre esta función es importante el desarrollo en René Girard, La violence et le sacré, Grasset, París, 1972.
} 
Conforme a la idea lineal del tiempo de nuestra civilización, es imposible eliminar la venganza ${ }^{7}$. Pero esa pulsión vindicativa que el poder punitivo canaliza -y que es civilizatoriamente normal en casos de delitos aberrantes-, la criminología mediática, mediante la invención de una nebulosa idea del delincuente como siempre bomicida y violador, crea una categoría aplicable a todos los sometidos al poder punitivo: según esta realidad mediática, en la cárcel sólo habría homicidas y violadores y, además, todos los victimizados por las policías latinoamericanas (ejecuciones sin proceso) también serían únicamente esos psicópatas.

Como la venganza es irracional, admitirla en una civilización que presume de racional $^{8}$ resulta vergonzante. Por eso, las teorías ordenadas por Bauer en 1830 también -desde esta perspectiva- son todas tentativas de ocultar la venganza mediante supuestos fines racionales. Se trata de una neurosis civilizatoria que provoca una reacción análoga al rechazo al inconsciente freudiano: somos racionales, aunque sepamos que no lo somos.

La criminología mediática, al difundir la fake new del poder punitivo reservado a homicidas y violadores, también pretende ocultar la venganza, aunque su ambivalencia resulte tan neurótica como la de un exhibicionista pudoroso. Para disimular su desmedida apelación a la venganza, asigna al poder punitivo un supuesto efecto disuasorio desnudo, diferente al de toda la restante coerción jurídica.

Es obvio que toda la coerción jurídica cumple una función disuasoria configuradora de la sociedad, pero siempre a través de los fines específicos de sus sanciones: así, la coerción civil

\footnotetext{
7 En civilizaciones con tiempo circular, ondulante o puntual sería posible, pero en la nuestra es imposible concebir que lo que pasó no haya pasado. Nietzsche en Also sprach Zarathustra lo dice muy claramente: cuando Zarathustra se libera, lo hace del tiempo lineal y, por ende, de la venganza, que es contra el tiempo. Esta es la gran dificultad que el abolicionismo no suele tomar en cuenta.

8 En realidad, nuestra civilización tiende a manejar un concepto meramente funcional de razón, que poco tiene en común con las concepciones más metafísicas.
} 
nos disuade de violar un contrato, pero a través de una sanción con función reparadora, a diferencia de la disuasión del poder punitivo, que se pretende desnuda de toda otra función.

La versión völkisch-populachera mediática-, para disimular pudorosamente su descarada apelación a la venganza, da por descontado el efecto disuasorio de las penas en hechos gravísimos, cuando precisamente en esos casos es evidente que no lo tiene, porque los crímenes más horripilantes son los más cercanos a conductas psicopáticas y, por ende, éstos son sobre las que menos posibilidades existen de disuasión mediante coerción jurídica? ${ }^{9}$.

\section{Las legitimaciones según la imaginería social penalística}

La fantasía penalística, empeñada en imaginar cómo debería ser el poder punitivo, se traduce en una riquísima imaginería social, que lleva casi un milenio de esfuerzos que, como todo lo humano, tiene límites y, por consiguiente, no puede evitar caer en reiteraciones.

La creatividad de los penalistas se dividió en dos grandes corrientes troncales por las que imaginaron cómo debería ser el poder punitivo y, por ende, sus respectivos límites: (a) unos imaginaron que debía recaer sobre seres más o menos iguales y libres, como retribución del daño causado por el mal uso de su libertad; (b) mientras para otros, recaería sobre seres humanos inferiores y determinados al mal, para neutralizar posibles males futuros.

La primera corriente imaginativa se subdividió (a) entre quienes acabaron imaginando que el poder punitivo debería ser la indemnización por la violación de un metafórico contrato social y, (b) quienes, sabiendo que los seres libres con

9 El supuesto efecto disuasorio en delitos muy graves se inventa conforme a una antropología aberrante, que fantasea que un asesino serial o cualquier otro cercano a la psicopatía, antes de cometer sus crímenes, consulta el código penal como si fuese una lista de precios. Se trata de una versión extrema del homo economicus, que directamente raya en el ridículo. 
determinables, imaginaron que el poder punitivo debería tener esa función. (c) Por supuesto que entre ambas surgieron todo tipo de combinaciones ${ }^{10}$.

Los primeros (a) imaginaron el deber ser del poder punitivo sobre bases metafísicas. Comenzaron creyendo que debía ser una retribución para expiación del pecado, para desplazarse al campo laico como reparación por violación del metafórico contrato social. Esta línea se inició con los glosadores y postglosadores $^{11}$ y alcanzó su más alto vuelo con el criticismo kantiano ${ }^{12}$.

(b) Los segundos partieron del empirismo e imaginaron un poder punitivo con la función práctica de determinar a seres determinables, conforme a castigos y premios, en procura de la mayor felicidad de todos. Su expresión más pura fue el pragmatismo de Bentham ${ }^{13}$.

La segunda corriente troncal (b) que imagina un poder punitivo destinado a ejercerse sobre seres inferiores, reconoce bases románticas ${ }^{14}$, subdividiéndose entre (a) idealistas y (b) pretendidos empíricos.

(a) Los idealistas clasificaron a los humanos entre libres y no libres, reservando la pena para los últimos, como $\mathrm{Hegel}^{15}$, o bien imaginaron que el poder punitivo debía cumplir una función de mejoramiento moral respecto de quienes se

10 Obedece a que en el iluminismo convergieron ambas corrientes, es decir, la metafísica y la empírica.

11 Es lo que se conoce como recepción del derecho romano. Estos primeros penalistas trabajaban a partir de los Libris terribilis del Digesto, pero también recibían la influencia de la filosofía griega.

12 Dentro del criticismo, Feuerbach se apartó de Kant con su teoría de la coerción psíquica o psicológica, resultado de su diferente fundamento de la separación entre moral y derecho.

13 Influyó en el pensamiento posrevolucionario francés y en el código de Napoleón.

14 Entendemos por tal el pensamiento que, a partir de cierta intuición o visión general, procura principios infinitos.

15 El hegelianismo penal limita la pena a quienes alcanzan la autoconciencia; a los otros les niega la capacidad de actuar con relevancia jurídica (colonizados, inimputables, multireincidentes, etc.). 
atrasaban en el proceso universal de fraternidad cósmica, como los krausistas ${ }^{16}$.

(b) Los pretendidos empíricos ${ }^{17}$ inventaron una etiología criminal debida a inferioridad biológica y se centraron en el peligro $^{18}$ de futuros males causados por los inferiores, a quienes el poder punitivo debería neutralizar o eliminar, para evitar la contaminación del pecado (mujeres estructuralmente inferiores para los demonólogos ${ }^{19}$ ); para eliminar las células infecciosas no evolucionadas del organismo social (criminales natos y colonizados para los positivistas del siglo XIX $)^{20}$ o para preservar la pureza de la raza aria superior evitando su involución (arios degenerados $^{21}$ para los nazis) $)^{22}$.

\section{III. ¿Qué se discute cuando se discuten las legitimaciones del poder punitivo?}

¿Qué son todas estas creaciones imaginarias de la fantasía penalística que llevan a que cada uno crea que el ejercicio del poder punitivo deba servir a distintos fines? Cada una de estos productos de la imaginación se concreta en una imagen de la

16 Da lugar a la teoría correccionalista o del mejoramiento (Besserungstheorie) de Röder, que tuvo acogida en España (por ejemplo, Concepción Aremal) y con la que disputó Carrara, quien por razones cronológicas nunca discutió con los positivistas.

17 El empirismo de los positivistas era falso, pues nadie puede probar el organicismo social, sin contar con las ridículas afirmaciones de Spencer y su racismo antropológico.

18 En razón de la peligrosidad, en realidad se penan eventuales delitos futuros, no cometidos y ni siquiera pensados, en tanto que el realmente cometido tiene sólo un valor sintomático.

19 La brujería implicaba un pacto con Satán, que sólo podían consagrarlo humanos inferiores en fe, moral e inteligencia, que serían las mujeres.

20 Los criminales natos tenían para Lombroso características mogoloides o africanoides.

21 El poder punitivo nazi se reservaba a los arios, los judíos y gitanos fueron eliminados en virtud de derecho administrativo policial.

22 La degeneración era un concepto que provenía de la psiquiatría de Morel, se aplicaba -entre otros- a los mestizos, lo que sostuvo hasta entrado el siglo XX la escuela psiquiátrica de Argel. En Latinoamérica, la degeneración de mulatos y mestizos, fue sostenida en la criminología biológica, expresamente por Raimundo Nina Rodrigues, considerado como fundador de la criminología brasileña. 
sociedad (imaginería social) que, de ser coherente, demanda un proyecto de estado que la configure, o sea que, en último análisis, los penalistas están discutiendo modelos de estado.

Según que el penalista asuma la actitud subjetiva de horripilante o garantista, legitimará más o menos ejercicio del poder punitivo y, por ende, también la sociedad y el modelo de estado que la configura, compatible con el mayor o menor ámbito de ejercicio de ese poder. Es claro que esta discusión corresponde al núcleo más central de toda discusión política, materia en la que es imposible lograr un general consenso.

Pero, además, los discursos legitimantes del poder punitivo parecen partir de alucinaciones o de ensoñaciones porque, al menos los penalistas garantistas, suelen imaginar un modelo de estado del que deducen la función de la pena, pero dan por existente el estado imaginado, o sea, la legitimación se basa en una alucinación. En el caso de los penalistas borripilantes, por lo general, se opta por reconocer que el estado existente o postulado no es ideal, sino transitorio, que permitiría el paso al ideal estado futuro, o sea una ensoñación ${ }^{23}$.

Pese a que toda esta discusión hace al Kernel de la cuestión política, la ciencia jurídico penal no parece ser consciente de su naturaleza. Contribuyen a ocultarla los indecisos, que suelen elegir varios fines del abanico de las teorías de la pena, para combinarlos -o amontonarlos-, como si de la acumulación de errores pudiese surgir la verdad ${ }^{24}$, como también los incoherentes, de corta capacidad imaginativa, que les impide llevarla hasta el final. Estas y otras contradicciones acaban creando un ensordecedor barullo ideológico.

Por cierto, no cabe duda que los cultores del derecho constitucional y político se hallan en el mismo tembladeral, pero la

23 Sea la Ciudad de Dios, una vez vencidas las socias de Satán, el estado racial puro de los arios germánicos, una vez eliminados los degenerados, el comunismo después de la dictadura del proletariado, el derrame de riqueza después de la concentración, etc.

24 Esta observación acerca de las llamadas teorías mixtas o combinatorias, la formula, Anton Bauer en op. cit. Obsérvese, además, que la combinación de teorías habilita la arbitrariedad, pues posibilita al juez elegir la más conveniente para una mayor o menor penalidad. 
diferencia finca en que lo saben y, por ende, se hacen cargo del material que manejan, pero a quien se asoma a la ciencia penal y se le muestra el cuadro de las teorías de la pena como algo limitado a ésta, se le oculta que se sumerge en el tema central de la discusión política y, por ende, a la vez que el barullo ideológico lo aturde, no comprende la naturaleza del aquelarre que vivencia.

\section{La criminología etiológica y la ciencia penal}

La variable (b) de la segunda gran corriente de la imaginería social penalística (b), es decir, los pretendidos empíricos que legitimaban el poder punitivo en la supuesta necesidad de neutralizar futuros males por parte de los inferiores (peligrosidad), fue inaugurada por los demonólogos misóginos (primera criminología etiológica) ${ }^{25}$, pero en su variable evolucionista (inferiores por no evolucionados) renació en la segunda mitad del siglo XIX, no contra las mujeres ${ }^{26}$, sino contra los europeos marginados del sistema productivo ${ }^{27} \mathrm{y}$ los colonizados ${ }^{28}$.

Esta segunda demonología fue admitida en las academias, al comienzo con el nombre de antropología criminal, porque se enmarcaba en la antropología colonialista racista (Spencer) ${ }^{29}$ que, con pretensión de ciencia natural, empírica y evolucionista,

25 La explicación de la inferioridad genética de la mujer era disparatada e insólita: sería inferior porque provenía de una costilla curva del pecho del hombre, por lo que contrastaba con la rectitud de éste.

26 Cabe aclarar que Lombroso seguía considerando inferior a la mujer, cuya baja incidencia en la prisionización atribuía a la prostitución, que la consideraba un equivalente femenino del delito.

27 El proceso de acumulación originaria fue precedido por un desplazamiento masivo de población hacia las ciudades, donde el incipiente capital productivo no estaba aún en condiciones de incorporar a toda esa masa que quedaba como marginal en las urbes europeas.

28 Los demonólogos no tuvieron que justificar el colonialismo, en tanto que el colonialismo originario se legitimó con argumentos teocráticos, pero el neocolonialismo lo hizo con el racismo, o sea, con pretendidos argumentos científicos.

29 Como estos discursos se basaban en la teoría de la evolución de las especies, se conoce a este racismo como darwinismo social, pero en realidad Darwin no llegó a estos extremos, su teorizador fue el ingeniero de ferrocarriles británico Herbert Spencer. 
quería explicar el delito como la manifestación de seres humanos biológicamente inferiores y peligrosos, semejantes a los salvajes colonizados. Luego fue rebautizada como criminalogía y por último criminología ${ }^{30}$, siendo como tal reconocida académicamente y cultivada por médicos en estrecha ligazón con policias ${ }^{31}$, que reparaban en los casos más graves y patológicos de criminales patibularios (el criminal nato $)^{32}$, lo que hasta ahora facilita la fake new mediática de prisiones llenas de homicidas y violadores. Ante la evidencia de que no todos los presos eran criminales natos, incorporó luego la categoría de ocasionales y algunos datos sociales aislados como causas del delito $^{33}$.

Esta nueva demonología se integró con la versión llamada positivista de la ciencia jurídico penal peligrosista y legitimó el poder punitivo policial en sociedades muy estratificadas, tanto metropolitanas ${ }^{34}$ como neocolonizadas $^{35}$, bajo el rótulo de defensa sociaß ${ }^{36}$, expresión que evoca guerra y enemigo ${ }^{37}$.

30 Este es el título del libro de Rafael Garofalo, que sintetiza los argumentos más racistas y degradantes de la dignidad humana de toda la criminología etiológica, pues consideraba que la lucha contra el delito es una guerra y que los pueblos colonizados equivalen a los criminales natos.

31 La corporación médica, desde el siglo XVI con Wier, intentaba hegemonizar el discurso penal, pero fue en el siglo XIX, cuando el control policial, importado de las colonias a las metrópolis, adquiría poder y las policías carecían de discurso, que los médicos, que disponían de discurso pero no de poder, se prestaron a la entente entre ambas corporaciones y los forenses se adueñaron del discurso criminológico.

32 Otrora llamados locos morales (moral insanity) por Pritchard y hoy se los llamaría psicópatas.

33 Por influencia de Ferri, Lombroso publicó un libro sobre las causas sociales del delito, con algunas afirmaciones absurdas sobre nuestra región.

34 Desde hacía tiempo las sociedades europeas se preocupaban por las clases peligrosas, a tal punto que en 1838 el Colegio de Francia convocó a un concurso con ese nombre, diez años antes de que Marx y Engels se refirieran a las clases en el Manifiesto. El concurso lo ganó un comisario de París: Fregier.

35 En nuestras sociedades, el positivismo de fines del siglo XIX no sólo sirvió para legitimar el poder policial, sino el régimen mismo de nuestras repúblicas oligárquicas que lo adoptaron como ideología oficial y lo difundieron por nuestras universidades, donde fue largamente dominante hasta mediados del siglo pasado. Así, fue filosofía oficial del porfiriato mexicano, del patriciado peruano, de la República Velha brasileña, de la oligarquía vacuna argentina, etc. 
La función leucocitaria de defensa social asignada al poder punitivo consistiría en neutralizar los gérmenes patógenos del organismo social $^{38}$ y de legitimar el neocolonialismo ${ }^{39}$. Al pretender un fundamento empírico, consideró la discusión política de los penalistas anteriores ${ }^{40}$ como una etapa precientífica superada ${ }^{41}$.

Los demonólogos habian integrado el saber penal con la criminología biológica como etiología del mal (inferioridad de la mujer) en un sistema que abarcaba las manifestaciones (pacto con Satán, brujería), el método para investigarla (tortura), la política criminal (la castidad) y la solución neutralizardora (purificación por el fuego) ${ }^{42}$. Los positivistas del siglo XIX y

36 La idea de defensa social era originaria de Romagnosi y seguida por Carmignani, pero fue retomada por Ferri. Después de su ocaso se promovió una nueva defensa social como política criminal, bastante confusa.

37 Hace pocos años, un artículo del Günther Jakobs, referido al derecho penal del enemigo, provocó un escándalo y dio motivo a una extensa bibliografía, cuando en realidad, en el derecho penal siempre hubo enemigos, sólo que no se empleaba esa terminología, de modo que, si el profesor de Bonn hubiese usado otros vocablos para decir lo mismo, probablemente no hubiese desatado ninguna polémica.

38 Los excepcionales inferiores criminales natos metropolitanos (atávicos parecidos a los colonizados) eran recluidos en prisiones, lo que hace pensar que las colonias, dado que contenían a seres igualmente inferiores, eran en realidad inmensas prisiones.

39 Las colonias eran territorios extranjeros ocupados policialmente, es decir, inmensos campos de concentración y de trabajo forzado para inferiores biológicos no evolucionados, en tanto que los delincuentes natos europeos eran atávicos, es decir, regresivos que volvían a la condición racial de los colonizados.

40 La discusión política iniciada en el siglo XVIII era un discurso funcional a la burguesía en su lucha contra la nobleza, pero cuando esa burguesía se instaló en el poder y pasó a ejercer la represión, ese discurso le resultaba disfuncional y, por tal razón, abrazó el del control y vigilancia policial de los marginados, trayendo de las colonias la técnica de ocupación policial del territorio.

41 Ferri consideró que todos ellos correspondían a una etapa metafísica que, conforme a Comte, era previa a la científica positivista por él representada, razón por la que inventó una escuela clásica que nunca existió y a la que relegó en una misma bolsa a todos los penalistas anteriores, pasando por alto sus dispares ideologías (aristotélicos, contractualistas, criticistas, hegelianos, krausistas, pragmáticos, etc.).

42 La articulación más acabada de este sistema integrado de criminología etiológica y ciencia penal inquisitorial se expuso en un libro tardío, pero que recoge toda la experiencia 
buena parte del XX también integraron su criminología etiología del delito (inferioridad de los estereotipados), en un sistema que abarcaba los signos de inferioridad biológica peligrosa (el delito y la mala vida ${ }^{43}$ ), el método para detectarla (vigilancia policial), la política criminal (moralidad pública) y la neutralización (resocialización $n^{44}$ o eliminación ${ }^{45}$ ).

En el modelo positivista integrado, como la criminología etiológica estaba dominada por los médicos y la ciencia jurídica era tributaria de sus enseñanzas (la peligrosidad la pronosticaban los médicos) ${ }^{46}$, esta última ciencia quedaba subordinada al saber médico; la criminología etiológica amenazaba con tragarse al derecho penal ${ }^{47}$.

Un modelo integrado positivista pero más moderado, asignó a la ciencia jurídico penal la función de contener al poder policial, como límite a la política criminal de erradicación del delito a cualquier precio, lo que hubiese llevado a un estado policial ${ }^{48}$. De toda forma, la verdadera ciencia seguía siendo la criminología etiológica, puesto que la doctrina penal era un

anterior, que es el Malleus Maleficarum o Martillo de las brujas, de Sprenger y Krämer, aunque en realidad parece que lo escribió Krämer en su casi totalidad.

43 Como el delito cometido tenía sólo valor sintomático, a su lado podía haber otros síntomas de peligrosidad predelictual (peligrosidad sin delito), entre los que se señalaba la mala vida, una suerte de amontonamiento de todo lo que la policía consideraba peligroso. Por eso, aparecieron las leyes de peligrosidad sin delito y, en el exptremo, se proyectó un código penal sin parte especial (proyecto Krylenko para la Rusia soviética).

44 Esta la reservaban para los delincuentes que consideraban ocasionales.

45 En todos los tiempos los delitos graves se penaron con la muerte, pero el problema eran los multireincidentes y reiterantes, Ilamados habituales, que nunca cometían un delito grave. Los países colonialistas como Gran Bretaña y Francia los remitían a las colonias como pena de relegación en forma de prevención especial negativa (Australia, Isla del Diablo), entre nosotros se practicaba la incorporación forzada al ejército (Martin Fierro), ambas racionalizadas luego por el positivismo policial como medidas de seguridad para delincuentes habituales.

46 Los diagnósticos criminológicos estaban a cargo de gabinetes dirigidos por médicos.

47 Era la tesis sostenida por Pedro García Dorado Montero, profesor de Salamanca, con su derecho protector de los criminales.

48 Fue la variable alemana del positivismo, encabezada por Franz von Liszt. 
saber práctico ${ }^{49}$, destinado únicamente a impedir el desborde del poder policial $^{50}$.

\section{V. ¿Una ciencia penal independiente y útil a cualquier modelo de estado?}

Dado que a fines del siglo XIX la ciencia jurídico penal se debatía entre la abierta discusión política imaginando modelos de estado (racionalismo metafísico del siglo XVIII), y la negación de su carácter científico, subordinándola al saber médico (positivismo peligrosista del siglo XIX), se propuso evadir esta opción. Para eludir la primera alternativa, se proclamó como una ciencia politicamente aséptica; para escapar a la segunda, se identificó como una ciencia de la cultura, impermeable a todo dato contaminante proveniente de cualquier ciencia natural.

Esa construcción fue obra del neokantismo jurídico penal ${ }^{51}$, basado en una teoría del conocimiento que separa radicalmente las ciencias naturales de las culturales $^{52}$. Las naturales seríon empíricas y regidas por la verificación; las culturales o del espíritu, por el contrario, se ocuparían del mundo de la libertad y no sería posible conocer sus objetos sin un previo ordenamiento.

El derecho pertenece a estas últimas y lo que pondría orden en sus objetos serían los valores, sin los cuales, si bien pueden existir otros entes, al no estar ordenados por los valores, el 49 Confrontaba con Karl Binding, que sostenía una teoría de los imperativos, legitimando las
normas por el mero hecho de emanar del estado.

50 Respondía a los tiempos de Guillermo II, en que el imperio intervenía económicamente y concedía algunos beneficios a la clase obrera, para detener el avance del socialismo y no caer en el estado policial. La confrontación con Binding respondía a que este último teorizaba en los tiempos de Bismarck, es decir de la unidad alemana. Esta confrontación era -en definitiva- de modelos de estado en Alemania. Aunque se la suele considerar análoga a la de clasicismo y positivismo inventada por Ferri en Italia, era por completo diferente.

51 Es el Ilamado neokantismo sudoccidental o de Baden, de Windelband y Rickert, que de los dos caminos que había dejado abiertos el criticismo de Kant (razón pura y razón práctica), optaba por el segundo.

52 Esta separación de las ciencias provenía de Wilhelm Dilthey. 
conocimiento no puede acceder a ellos ${ }^{53}$, de modo que el valor determinaría los límites epistemológicos de la ciencia jurídica.

Esta teoría del conocimiento tiene dos importantes consecuencias: (a) por un lado, los datos sociales no ordenados por los valores, no tienen cabida en la ciencia jurídico penal y, (b) por el otro, no es pertinente la pregunta sobre quién impone los valores, porque la respuesta sería un dato verificable, propio de una ciencia natural, por lo que tampoco tiene cabida en una ciencia cultural como la jurídico penal.

Como los valores pueden corresponder a cualquier forma de estado $^{54}$, la ciencia penal sería una lógica normativa destinada a dar completividad (no contradicción interna) a un sistema de interpretación de los entes que el valor había ordenado, dejando fuera de su horizonte de proyección todos los datos sociales que no ordenados por los valores.

Si bien esta metodología desintegra el sistema en que el positivismo integraba la criminología etiológica, no deja de integrarla de un modo diferente, en que esa criminología queda subordinada a la ciencia jurídico penal, como saber auxiliar ${ }^{5}$.

En efecto: para el neokantismo, la ciencia jurídico penal le indica a la criminología etiológica cuáles son las conductas cuyas causas esta última debería explicar ${ }^{56}$. La criminología

\footnotetext{
53 Se sostiene que no se trata de un idealismo porque no niega la realidad de los entes. pero en esa selección que determina la posibilidad de conocimiento, si bien el conocimiento no crea el objeto, no puede ocultarse cierto grado de creación o, al menos de negación, al dejarlo fuera del conocimiento; se trataría siempre de una creación de realidad, sino por acción al menos por supresión.

54 El neokantismo penal dio lugar a construcciones liberales, como las de Gustav Radbruch y Max Ernst Mayer, pero también a un desarrollo adecuado a la legislación nazi, como las de Edmund Mezger y Wilhelm Sauer, entre otros muchos de su tiempo (al respecto, nuestro Doctrina Penal Nazi. La dogmática penal alemana entre 1933 y 1945, EDIAR, Bs. As., 2017).

55 Esta fue la forma en que por muchos años se enseñó criminología en Latinoamérica.

56 Se trataba de una criminología etiológica que se seguía enseñando en las facultades de derecho; podemos decir que fue la criminología del rincón de la facultad de derecho. Conforme a los presupuestos neokantianos, no deja de haber una contradicción en esta nueva integración, puesto que una ciencia cultural define los límites epistemológicos de una ciencia natural.
} 
etiológica pasa así de hegemónica a subordinada, pero sin mayores alteraciones, salvo en algún matiz plurifactorial ${ }^{57}$.

\section{La sociología avanza por su lado}

Mientras se llamaba sociología criminal a los pocos datos sociales que hacían a las pretendidas causas sociales del delito con las que el positivismo había espolvoreado su criminología biologista, integrada como rectora de la ciencia jurídico penal, la sociología general se desarrolló en las últimas décadas del siglo XIX con independencia de ésta. Más aún: la versión funcionalista de la sociología general desmintió la idea de absoluta dañosidad social del delito de la criminología positivista ${ }^{58}$.

Los aportes de los padres fundadores de la sociología general (Weber, Durkheim, Simmel, Tarde) impactaban a la ciencia jurídica en general, encerrada en el formalismo dogmático, incluso en el propio Jhering, artífice de la formulación moderna del método dogmático ${ }^{59}$. De este modo, la sociología general hizo nacer la sociología jurídica, preferentemente cultivada por privatistas o publicistas ${ }^{60}$ y centrada en el derecho como fenómeno social, siendo incluso receptada metodológicamente por la ciencia jurídica, hasta generar la llamada escuela del derecho libre $^{61}$ y el realismo jurídico norteamericano ${ }^{62}$. Pero sin llegar a esas posiciones tan radiclaes, entre la metodología

\footnotetext{
57 Fueron sumándose nuevos conceptos biologistas, como los surgidos de los primeros tiempos de la endocrinología, con las biotipologías de Ernst Kretschmer, de Nicola Pende y otros.

58 Émile Durkheim sostuvo la normalidad del delito, afirmando que en toda sociedad se requiere una cantidad normal de delito, que cumpliría la función de reforzar la cohesión social y cuyo excesivo descenso no sería un signo social positivo.

59 Rudolf von Jhering sistematizó las reglas de la moderna dogmática jurídica en analogía con el método de la química y distinguió la antijuridicidad de la culpabilidad en el campo del derecho privado. El giro lo dio en sus trabajos sobre el fin del derecho y el derecho como lucha. 60 Sus antecedentes pueden remontarse al romanticismo jurídico de Savigny y, posteriormente de Kirchmann.

61 Es la escuela de H. Kantorowicz

62 En especial el realismo jurídico norteamericano, con Holmes y Pound.
} 
y la sociología jurídicas se operó un creciente intercambio de aportes $^{63}$.

En este proceso se detecta nuevamente la anomalía de la ciencia jurídico penal, pues los sociólogos jurídicos no se centraban demasiado en el poder punitivo ni en el derecho penal. Tanto la sociología jurídica como las teorías generales del derecho, siempre percibieron cierta anomalía en la cuestión penal, que muchas veces se hizo manifiesta, incluso señalando algunos que la excluían expresamente de sus teorizaciones ${ }^{64}$.

Cuando al término de la Primera Guerra Mundial el primado de la sociología general pasó a Estados Unidos ${ }^{65}$, en la Universidad de Chicago se incentivó la sociología urbana y la preocupación por el delito, si bien siempre en sentido etiológico, aunque totalmente libre del lastre biologista del positivismo racista ${ }^{66}$.

Siempre que la pretendida etiología deja de ser biologista y pasa a ser socialógica, a poco se revela que, por excluir de las causas sociales al ejercicio del poder punitivo, se cae en una etiología social falsa, lo que se vuelve inocultable al ponerse en evidencia su inocultable arbitrariedad selectiva.

Así, la primera criminología etiológica (demonología) fue descalabrada discursivamente ${ }^{67}$ por Friedrich Spee, cuando se

63 La confrontación entre formalismo y antiformalismo fue el gran debate jurídico y sociológico jurídico del siglo XX, con Kantorowicz, Ehrlich, Gierrke, Holmes, Pound, Geny, Hauriou, Duguit, Gurvitch y otros por el lado antiformalista, y Kelsen en lo jurídico y Max Weber en lo sociológico, por el otro.

64 Asi, los teorizadores del trialismo no suelen referirse al derecho penal y algunos expresamente dicen que no puede utilizarse en esta materia.

65 Al final de la primera guerra (1914-1918) Europa quedó devastada y con una sensación general de pesimismo y decadencia, sus grandes maestros fundadores habían muerto y la sociología pasó a desarrollarse principalmente en los Estados Unidos, que había salido ileso de la guerra, vivía los locos veinte y recibía flujos migratorios que eran seleccionados por cuotas con criterio racista. El crecimiento acelerado de las ciudades incentivaba el interés sociológico.

66 En esta línea se destacaron las contribuciones de William I. Thomas y, sobre todo, la ecología urbana de Robert Ezra Park y Ernest W. Burgess, en la llamada primera escuela de Chicago.

67 Si bien la obra de Spee (Cautio criminalis) no demolió el poder académico de los demonólogos, fue el antecedente más fuerte de Christian Thomasius, que acabó por desbaratarlo setenta años más tarde, inaugurando el iluminismo alemán. 
desentendió de la discusión sobre la existencia de las brujas, para analizar la forma en que se ejercía el poder punitivo inquisitorial, revelando quiénes lo ejercían y los graves delitos que $\operatorname{cometían}^{68}$. Por primera vez se pone de relieve que los encargados de reprimir el delito eran los mayores criminales.

El proceso se reiteró en el siglo XX, cuando la criminología etiológica se volvió sociológica, haciendo cada vez más notorio que, de la exclusión epistemológica del poder punitivo, resultaba una etiología falsa, hasta que fue innegable su incidencia ${ }^{69}$, lo que terminó provocando un cambio de paradigma, en que ya no eran su principal objeto las causas del delito centradas en el delincuente -que dejaba de ser considerado un ser inferior y diferente-, para centrarse en el poder punitivo, con la llamada criminología de la reacción social ${ }^{0}$.

Esta criminología se dividió entre una corriente llamada liberal y otra radical. (a) La primera se nutrió del interaccionismo simbólico ${ }^{71}$ y de la fenomenología ${ }^{72}$ y fue necesariamente crítica del poder punitivo, especialmente con la teoría del etiquetamiento (labelling approach) ${ }^{73}$, que puso de resalto

68 Spee demuestra la responsabilidad de los teóricos de la teología, de los príncipes, la corrupción de los inquisidores, la perversión sexual de los verdugos, el objetivo reproductor de la tortura, la crueldad sádica de los jueces, la alquimia valorativa, la complicidad de los confesores borrachines, para concluir que con esa selección cualquiera sería considerado brujo y comparando ese ejercicio del poder punitivo con los crímenes de Nerón quemando cristianos.

69 Por ejemplo, la señalización de la intervención punitiva como generadora de desviaciones secundarias de conducta, condicionando futuras carreras criminales, de Edwin L. Lemert.

70 Es una denominación genérica que no refleja correctamente el alcance de esta criminología, porque no se trata de una reacción, sino de una interacción permanente. Esta criminología se difundió en Latinoamérica por la obra de dos criminólogas venezolanas, Rosa del Olmo y Lola Aniyar de Castro, entre otros autores (Roberto Bergalli, Juarez Cirino dos Santos, etc.).

71 Esta corriente también es Ilamada conductismo social, enunciada por George Herbert Mead, pero luego desarrollada como dramaturgia social por Erwin Goffman. En criminología se destacan las obras de Howard S. Becker y otros.

72 En especial la llamada etnometodología, pero es muy importante el trabajo de sociología fenomenológica de Berger y Luckmann.

73 Es resultado de la teoría de los roles en la dramaturgia social interaccionista, según la cual cada uno de nosotros termina siendo en alguna medida tal como nos ven los otros y conforme a los roles que nos demandan. 
-entre otras cosas- su selectividad estructural conforme a estereotipos y la función reproductora de las prisiones ${ }^{74}$.

(b) La segunda -radical- se orientó preferentemente por el marxismo no institucionalizado (Escuela de Frankfurt) ${ }^{75}$, objetando a la llamada liberal por no extenderse hasta el poder social al que es funcional el punitivo, con lo que, de una crítica criminológica se pasó a una crítica macrosocial. El resultado fue una marcada impotencia para proponer reformas, dado que poco podría hacerse antes de un profundo cambio también macrosocial.

De toda forma, la sociología general no marxista, incluso la tradicional ${ }^{76}$ y más aún la crítica liberal y el labelling, demolían las bases de la ideología de que era portadora la dogmática jurídico penal: desmentían por completo el principio de igualdad, el de legalidad, la idea de derecho penal de acto, la pretendida tutela igualitaria de bienes jurídicos, etc. ${ }^{77}$

De este modo, hace cuatro o cinco décadas, tanto la ciencia jurídico penal como la criminología crítica se hallaban en un callejón sin salida. La primera resultaba incompatible con el saber sociológico -incluso con el más tradicional- y, sintiéndose amenazada, se refugiaba en el neokantismo que, al excluir arbitrariamente los datos sociales, preservaba sus falsas bases ideológicas y sólo perfeccionaba su completividad lógica (no contradicción interna). Por la acera opuesta circulaba una sociología que había transitado de lo etiológico a la reacción social y, dentro de ésta, de la versión liberal a la radical, pero que, llegada a este límite, se dedicaba a combatir al capitalismo de las sociedades de consumo, sin posibilidad de incidir sobre el

\footnotetext{
74 La crítica a las instituciones totales de Erwin Goffman marcó un hito respecto de prisiones y manicomios.

75 Adorno, Horkheimer, Marcuse, etc. En criminología se destaca la obra pionera de Rusche y Kirchheimer, Pena y estructura social.

76 Como Robert Merton, la teoría de las subculturas, etc.

77 A este respecto es fundacional la crítica de Alessandro Baratta, Criminologia e dogmática penale. Passato e futuro del modelo integrato di scienza penalistica, en "La questione criminale", año V, n² 2, mayo-agosto de 1979.
} 
poder punitivo mientras éste sobreviviese. En semejante encrucijada era imposible concebir un nuevo modelo integrado de derecho penal y criminología ${ }^{78}$.

\section{La desintegración se torna insostenible}

En las décadas que siguieron tuvieron lugar cambios muy profundos en el poder mundial y regional: se acabó el mundo bipolar; se financiarizó la economía; el totalitarismo financiero se impuso al poder político asumiendo formas macrocriminales; se produjo el encarcelamiento masivo en ambos hemisferios; los adolescentes de barrios precarios y los inmigrantes son los nuevos estereotipados en nuestra región y los migrantes en el norte; el tardocolonialismo se ejerce en Latinoamérica por medio de endeudamientos astronómicos; tiende a desaparecer el welfare state; la riqueza mundial se concentra en el $1 \%$ de la humanidad; se acelera el deterioro del medio ambiente, provocando mutaciones virósicas que paralizan la economía global.

El totalitarismo financiero se legitima con un nuevo discurso reduccionista (economicista), basado en la antropología aberrante del homo economicus y la meritocracia, que cunde por las academias -hasta el Premio Nobel-, como ideología que confronta radicalmente con los Derechos Humanos ${ }^{79}$ y trata de arrasar con todas las ciencias de la conducta.

En nuestra región, con los coeficientes de Gini más altos del mundo, el tardocolonialismo intensifica la estratificación social, hace desaparecer los brotes de estados de bienestar y pretende cronicizar nuestro subdesarrollo, con alto costo de vidas ${ }^{80}$.

\footnotetext{
78 Esta imposibilidad era afirmada en ese artículo fundacional por Alessandro Baratta.

79 Es notoria la negación de los derechos humanos por parte de Friedrich von Hayeck, uno de los evangelistas de esta ideología, que afirma que nadie por el hecho de nacer tiene derechos. La participación de otro evangelista, Milton Friedman, en la programación económica de la dictadura chilena, revela que el autodenominado neoliberalismo nada tiene de liberal.

80 Si se sumasen las muertes causadas por los altos índices de homicidio de algunos países de la región, los suicidios (especialmente de personas de la tercera edad), la privatización
} 
El poder punitivo de nuestras sociedades se vuelve más violento, letal y selectivo, bajo la consigna völkisch de tolerancia cero, impulsada por la criminología mediática de los monopolios que reemplazan funcionalmente a los partidos políticos en forma de partidos únicos. El lawfare ${ }^{81}$ contra opositores populares y disidentes sería la envidia de Göbbels y Vichinski. Es inocultable la degradación de $\operatorname{los}$ Estados $^{82}$ y el discurso mediático se degrada a publicidad pura: los monopolios mediáticos, a fuerza de crear realidad, acaban desfondándola.

Debido a estos cambios, la crítica sociológica de hace cuatro décadas perdió buena parte de su vigencia, puesto que es de procedencia anglosajona y se originó frente al poder punitivo de sociedades capitalistas de producción y consumo ${ }^{83}$. Por su parte, nuestra ciencia jurídico penal continúa importando versiones renovadas del neokantismo ${ }^{84}$ y del neohegelianismo ${ }^{85}$,

de servicios de salud, la falta de campañas sanitarias y de vacunación, la atención selectiva de la salud, la inseguridad laboral, la inadecuación de la red caminera a los vehículos que nos imponen, etc., veríamos que anualmente resulta un número equivalente a una ciudad de regulares proporciones. Todas estas muertes son causadas por el subdesarrollo y las hemos considerado como un genocidio por goteo.

81 Esta denominación significa guerra de derecho, pero en realidad nada tiene que ver con el derecho, puesto que es resultado de bandas de delincuentes integradas por jueces prevaricadores en coautoría con agentes de inteligencia, funcionarios extorsionadores, testigos comprados, policías corruptos y difamadores disfrazados de periodistas, instigados por altos funcionarios de gobiernos y gerentes de corporaciones mediáticas monopólicas.

82 Los estados de derecho de la región se deterioran, pero no suelen marchar hacia estados de policía, sino hacia un debilitamiento del estado mismo, pues las autonomizaciones policiales, la letalidad policial, la concentración de la delincuencia de subsistencia en organizaciones, el surgimiento de grupos de autodefensa y de parapoliciales y milicias e incluso la intervención de fuerzas armadas en función policial, hace perder al estado el monopolio de la recaudación fiscal y del ejercicio del poder punitivo, es decir que pierde el monopolio de la coerción y también la defensa nacional, todo lo cual resulta funcional al tardocolonialismo financiero.

83 Esto exige una renovación de la propia criminología crítica que, necesariamente debemos llevar a cabo en la región, incorporando la experiencia de nuestra larga lucha contra el colonialismo y reorientándola hacia la forma actual que asume el poder punitivo del tardocolonialismo.

84 Es la dogmática jurídico penal dominante en Alemania en este momento, cuyo autor más difundido es Roxin. 
reforzando la inviabilidad de la incorporación de datos sociales a las construcciones jurídicas.

En este momento, entrados decididamente en este inquietante siglo XXI, se hace más acuciante la necesidad, por un lado, de reorientar la crítica sociológica al actual marco de poder y, por otro, de integrarla con la ciencia jurídico penal, pues en nuestra región, entre la imaginería penalística y la realidad, ya no media una simple disparidad sino un creciente disparate.

La progresiva irrealidad de la ciencia jurídico penal reclama con paralela urgencia su superación, dado que su anomalía deja de ser un drama académico, para implicar un creciente y gravísimo peligro social y político. Pese a la fuerte creación de realidad de los partidos únicos mediáticos, el disparate va siendo inocultable a nuestras poblaciones, con el riesgo de llevarlas a despreciar al derecho como herramienta social ${ }^{86}$.

El primer objetivo de todo cambio violento siempre fueron los símbolos del poder punitivo: los revolucionarios franceses tomaron la Bastilla pero, por estar vacía, no liberaron a ningún preso, sólo destruyeron el símbolo, pero finalmente, todo terminó en el terror.

\section{No es imposible la construcción de un nuevo sistema integrado}

Hace treinta años pensamos que esa encrucijada debía ser superada $^{87}$, en lo que ahora insistimos, sólo que con la mayor urgencia que imponen los cambios de las últimas décadas.

El camino de superación de la anomalía jurídica de la ciencia penal fue enunciado sintéticamente por Tobías Barreto, el

\footnotetext{
85 En alguna medida, puede considerarse de este modo el funcionalismo de G. Jakobs, que no tiene mayor predicamento en Alemania.

86 La violencia política siempre deja cicatrices y, además, aunque triunfen los más desfavorecidos, invariablemente ponen el mayor número de víctimas.

87 Lo esbozamos en nuestro ensayo En busca de las penas perdidas. Deslegitimación y dogmática jurídico penal, EDIAR, Bs. As., 1989.
} 
visionario jurista brasileño que encabezó la llamada escuela de Recife $^{88}$, cuya escueta señalización quedó en el olvido, sin que nadie las desarrollase, o sea, que pasaron casi inadvertidas para la ciencia penal latinoamericana, primero subordinada el positivismo racista spenceriano y luego deslumbrada con la importación acrítica de las construcciones de la ciencia penal alemana.

En 1886, reflexionando a partir de la lectura de Fröbel $^{89}$, Barreto dio en la clave de los principios que permitirían a la ciencia jurídico penal dar el giro al que se resiste: Quem procura o fundamento jurídico da pena debe tambem procurar, si é que ja não encontrou, o fundamento jurídico da guerra ${ }^{90}$.

Antes había afirmado -con toda precisión- que la pena no es un concepto jurídico, sino político ${ }^{91}$. Sus geniales intuiciones a este respecto se completan con la afirmación de que no existe un derecho natural, pero si una ley natural del derecho ${ }^{92}$.

A partir de estas claves, es posible comprender y cancelar la excepcional anormalidad de la ciencia jurídico penal en relación al resto de la ciencia jurídica.

Desde los tiempos de Barreto, el derecho internacional rectificó su rumbo, pero la ciencia penal no lo imitó. Los internacionalistas abandonaron el viejo derecho a la guerra, pues cayeron en la cuenta de que las guerras no se desataban conforme a

\footnotetext{
88 Tobías Barreto (1839-1889) fue un jurista bastante autodidacta, el primero en nutrirse de literatura jurídico penal alemana en nuestra región, con posiciones a veces contradictorias, pero innegable pensador independiente, que trabajaba en el Brasil profundo de un nordeste económicamente desarticulado por el desbaratamiento de la economía del azúcar y el paso a la del café del sur.

89 Julius Fröbel, Theorie der Politik, als Ergebniss einer Erneuerten Prüfung Demokratischer Lehrmeinungen, Vol. 1: Die Forderungen der Gerechtigkeit und Freiheit im State, 1861 (cfr. Deutsche Biograpihische Enzyklopädie, (herausgegeben Walter Killy), K.G. Saur, 2001, 3, p. 501).

90 Tobias Barreto, Obras Completas, V, Direito, Menores e loucos e Fundamento do direito de punir, Ed. do Estado de Sergipe, 1926, p. 151

91 Idem, p. 149.

92 Tobias Barreto, Obras Completas, VII, Estudos de Direito (vol. II), Ed. do Estado de Sergipe, 1926 , p. 38
} 
lo que ellos programaban en sus libros y, por ende, decidieron resignarse y pasar a proyectar la limitación de sus extremos de crueldad. De este modo, quedó raquítico ${ }^{93}$ el derecho a la guerra y se desarrolló el derecho internacional humanitario ${ }^{94}$ que, en lugar de teorizar la guerra para limitarla legitimándola parcialmente (con el concepto de guerra justa), procura ponerle límites.

El paralelo con el derecho penal es innegable: éste pretende, mediante sus teorías de la pena, limitar al poder punitivo legitimando su ejercicio en forma parcial (el poder punitivo justo, equivalente a la guerra justa). Los internacionalistas minimizaron las discusiones sobre la guerra justa (el poder punitivo justo del derecho penal), para centrarse en la neutralización de sus desmanes (equivalente en el derecho penal a la limitación del poder punitivo). Por cierto, se trata de una cara señal de realismo y humildad humana del internacionalismo jurídico, que no pretende ya dictarle reglas al poder bélico, indicándole cuándo debía desatarse, sino que se centra en evitar en lo posible sus letales consecuencias. La soberbia penalista todavía nos impide dejar de pretender indicarle al poder político hasta dónde puede usar el poder punitivo definiéndole modelos de estados, para centrarnos en las limitaciones a sus también letales consecuencias.

En verdad, en cuanto a la relación entre la guerra y la política, es difícil saber cuál de ellas es continuación de la otra (si le asistía la razón a Clausewitz o a Foucault), pero el vínculo entre ambas es innegable. Tobías Barreto lo percibió mucho antes del desarrollo actual del derecho internacional humanitario, pero, actualizando el sentido de sus palabras, podemos decir que en el momento bélico opera como agencia jurídica la Cruz Roja Internacional, en tanto que en el momento político -al menos cuando sirve a un estado que quiere aproximarse al modelo de derecho- este papel lo debe asumir el poder jurídico de contención programado por la ciencia jurídico penal.

\footnotetext{
93 Podría considerarse que tienen por base la Carta de la ONU.

94 Las bases legales del derecho internacional humanitario son los Convenios de Ginebra y sus protocolos adicionales.
} 
Consideraríamos absurdo que el derecho internacional presentase hoy un cuadro de teorias legitimantes de la guerra, pero nos sigue pareciendo normal que la ciencia jurídico penal, para legitimarse, quiera legitimar un factum politico perdiéndose en el abanico de teorías de la pena de Bauer, incluso sin consciencia de que discute modelos de estado que sueña, como producto de la imaginería penalística. El derecho internacional logró erradicar el hábito normalizador de legitimar la guerra justa, que aún hoy pesa sobre el derecho penal, la legitimar el poder punitivo justo.

\section{No es posible conocer todas las funciones del poder punitivo}

Dado que el poder punitivo es un hecho político -y como tal en extremo plurifuncional- no es posible que tenga una única función, como no la tienen las guerras. Por otra parte, dada la extrema variedad de conflictos en que interviene, tampoco es posible conocer todas sus funciones, disfunciones y consecuencias en la realidad social, algunas de las que ni siquiera sospechamos ${ }^{95}$.

No obstante, penalistas, jueces y políticos parecen internalizar una autocensura impuesta por la tradición académica y reforzada por la criminología mediática alienante de nuestros partidos únicos, que difunde una idolatría del poder punitivo, pues lo convierte en un falso dios, dotado de un blasfemo carácter omnipotente. Para los fanáticos de este ídolo -que no es de oro-, es una cuestión de $f e^{96}$, no habiendo nada que no pueda resolverse con su ejercicio.

\footnotetext{
95 Es claro que la función de la pena o de su amenaza en un delito tributario no es la misma que en un homicidio calificado, o la de un delito de libramiento de cheque sin provisión de fondos tampoco es igual a la de un delito de violación. Además, el poder punitivo puede tener consecuencias que nadie haya previsto: incidir sobre primas de seguros, favorecer la preferencia por cierto modelo de vehículos, determinar oscilaciones en el precio de los inmuebles de cierta zona, difundir el uso de armas de fuego, impedir reuniones, afectar formas de vida, etc.

96 Este carácter de cuestión de fe fue señalado hace años por la criminóloga canadiense Ruth Morris.
} 
Por esa razón, frente a las teorías de la pena y a la idolatría punitivista, cabe una posición agnóstica, que no niegue su poder, pero sabiendo que no es omnipotente y que no conocemos -ni podemos conocer y quizá nunca podremos conocer- todas sus funciones y consecuencias. Tampoco es posible ignorar que puede tener efectos positivos, para lo cual no es necesario adherir al funcionalismo de Durkheim o a otros semejantes, bastando con saber que, si el bien absoluto no es de este mundo, tampoco lo es al mal absoluto.

Nunca podemos ignorar su poder, porque es incuestionable y está harto verificado que, cuando el poder punitivo se expande y el poder jurídico limitador se reduce, el estado se aleja del modelo ideal de derecho, para aproximarse al de policía o para debilitarse disuelto en ejercicios paralelos y subterráneos ${ }^{97}$. En el primer caso se tiende a un totalitarismo; en el segundo a un debilitamiento y degradación del estado, que pierde la hegemonía del poder de coerción y de recaudación fiscal ${ }^{98}$.

Es interesante y curioso observar que todos los penalistas que encuadran su saber jurídico en el marco de un estado que aspira a aproximarse al modelo de derecho, se reivindican como continuadores del Iluminismo. No hay penalista en el mundo que pretenda elevar monumentos ni bautizar institutos y academias con el nombre de Torquemada o de los demonólogos, a los que incluso se los niega y hasta oculta como precursores.

Llama poderosamente la atención que la programación de jurisprudencia prudente ${ }^{99}$ de los penalistas que reivindican el

\footnotetext{
97 Esta multiplicación de sistemas penales tiene lugar en todo estado de policía, como lo señaló Lola Aniyar de Castro, siendo todos funcionales a una cúpula política fuerte.

98 En los estados deteriorados también se pluralizan los sistemas penales, pero sin cúpula política fuerte, sino que acaban pluralizándose sus agencias recaudadoras, que ejercen el poder punitivo como coerción necesaria para recaudar, lo que formalmente se llama corrupción y extorsión.

99 Nos referimos a los penalistas garantistas, llamados también liberales, expresión que tratamos de evitar para no generar confusiones con el arrastre fangoso de este término por la ideología opuesta a los derechos humanos que encubre hoy al totalitarismo financiero.
} 
valor histórico positivo de la función de contención y teorizan jurídicamente en estados cercanos al modelo de derecho, no se percaten de la necesidad (a) de desterrar el hábito de pretender acotar el poder punitivo imaginando modelos de estados y alucinando su existencia, en lugar de legitimar de modo casi exclusivo o totalmente predominante la función limitadora y operar con racionalidad a partir del estado existente, ni (b) de abandonar la ilusión de que sus destinatarios (operadores jurídicos) ejercen poder punitivo, cuando lo único que pueden hacer, en el legítimo ejercicio de su poder jurídico, es contenerlo y acotarlo dentro de límites racionales y humanos, para evitar sus desbordes letales para las personas y los estados de derecho realmente existentes.

\section{La relegitimación mediante una nueva integración}

Para legitimarse, la ciencia jurídico penal no tiene más que limitarse a reconocer y reivindicar su carácter de programadora de decisiones jurisprudenciales de acotamiento del poder punitivo, cuyo beneficio se pone de manifiesto apenas se observa el resultado genocida que en el siglo pasado tuvo el debilitamiento del poder jurídico de contención, que es su indispensable y legítima incumbencia.

La ciencia jurídico penal se legitima al incorporar y empalmar con las críticas sociológicas al poder punitivo, como constructora de sistemas dirigidos a los operadores jurídicos, para que su jurisprudencia opere los filtros que interfieran el paso del poder punitivo más irracional, selectivo, discriminador, racista, violento, etc. Los caracteres del delito son diferentes niveles de selección, como compuertas del dique de contención jurídica al poder más groseramente violador de la igualdad, la libertad y la fraternidad.

La selectividad del poder punitivo es inevitable, dada (a) la disparidad de lo legalmente programado (criminalización primaria o in the books) y la limitada capacidad de las agencias ejecutivas (criminalización secundaria), como también en razón 
(b) del marcado entrenamiento diferencial en sociedades muy estratificadas, que provoca la captación policial de estereotipados autores de delitos groseros de subsistencia ${ }^{100}$.

Respecto de la selectividad como carácter inevitablemente estructural del poder punitivo, la ciencia jurídico penal debe esforzarse por procurar menores estándares, para lo que, ante todo, debe evitar su negacionismo, que es la peor de las injusticias sociales. Es tarea del derecho penal de acto ocuparse de disminuir hasta donde sea posible el ejercicio del poder punitivo de autor.

La dogmática jurídica debe construir sus conceptos y organizarlo en sistemas limitadores, como programa político destinado a la optimización del poder jurídico de contención del poder punitivo, en procura de la reducción de sus caracteres negativos y, por ende, como todo programa político, debe nutrirse de los datos sociales que le informan acerca del ejercicio real del poder que debe acotar, so pena de resultar delirante. Esta tarea de programación de la contención de un poder estructuralmente selectivo, importa la elevación de los estándares de realización de los principios constitucionales de igualdad y respeto a la dignidad humana en el plano de la realidad social.

Las información, los datos indispensables para llevar a cabo esta misión se los debe proporcionar a la ciencia jurídico penal la criminología y, dentro de ella, en principio la sociología ${ }^{101}$. Por ende, imitando de este modo el camino racional de

\footnotetext{
100 Las policías operan conforme a reglas comunes a toda burocracia, es decir, que hacen lo que es más sencillo. La investigación de conductas más sofisticadas, propias de las capas sociales superiores y con diferente entrenamiento, como el poder social de éstas, determina la impunidad de los llamados delitos de cuello blanco, lo que fue observado criminológicamente hace más de ochenta años por Edwin Sutherland y hace más de un siglo largo por Gabriel Tarde.

101 En general, la crítica proviene de la sociología, pero como las otras ciencias de la conducta habían sido aplicadas con sentido etiológico por la criminología de esta vertiente, aún no se ha operado del todo una reintroducción de estas disciplinas desde la perspectiva crítica, puesto que sufren una suerte de desconfianza por sospecha etiológica.
} 
humildad y racionalidad seguido por el derecho internacional respecto de la guerra, nos surge un nuevo sistema integrado de derecho penal y criminología.

\section{La onticidad del ejercicio del poder punitivo}

Aquí entra en juego la segunda advertencia de Tobías Barreto: dejando de lado la discusión jusfilosófica en torno al derecho natural o supralegal, lo importante es su afirmación de que existe una ley natural del derecho.

La ciencia jurídico penal interpreta leyes $\mathrm{y}$, ante todo, las del bloque de constitucionalidad (normas constitucionales e internacionales $)^{102} \mathrm{y}$, en segundo lugar, las infraconstitucionales, que deben ser interpretada siempre en el marco de las primeras $^{103}$.

Estas leyes, son válidas porque proceden de fuentes legislativas competentes, pero si además pretenden ser eficaces, deben producir efectos sociales acordes con su ratio legis o fin manifiesto. Pues bien: para que el intérprete elabore un programa dirigido a ese objetivo legal, debe verificar en qué medida se realiza en el mundo del ser ese deber ser-ante todo de las leyes de máxima jerarquía-, verificación que sólo puede llevar a cabo con la información social.

A diferencia de lo postulado por el neokantismo, el derecho no puede aislarse del mundo, permitiéndose seleccionar

\footnotetext{
102 Con frecuencia se observa en nuestra ciencia jurídico penal -y en nuestros jueces -una inversión del orden jerárquico de las normas, producto de una asimetría de fuentes doctrinarias. Todos nuestros estados regionales fueron -al menos en el plano teórico- estados constitucionales de derecho, pues copiamos cercanamente el modelo de la constitución norteamericana, con el pertinente control de constitucionalidad. No obstante, a la hora de elaborar nuestras doctrinas jurídicas, salvo en derecho constitucional, las importamos de Europa, o sea, de estados legales de derecho, que no conocían el control de constitucionalidad, puesto que éste se difunde en ese continente apenas a partir de la última posguerra. 103 El control de constitucionalidad -al igual que el de convencionalidad-puede descalificar una norma por incompatibilidad total con otra de mayor jerarquía, pero también puede emitir sentencias interpretativas, que condicionan la validez de la norma a cierta interpretación compatible con la de mayor jerarquía.
} 
arbitrariamente los datos que quiera incluir o excluir quien impone el orden de los valores, porque si bien el orden jurídico es un orden, hay otros muchos órdenes -dado que el mundo no es un caos- y cuando el derecho se refiere a un ente del mundo, debe respetar lo que ese ente es (su onticidad) en su respectivo orden (físico, biológico, económico, social, etc.). De no hacerlo, no dejará de ser válido ni de ser derecho, pero carecerá de eficacia, porque se dirigirá a un ente diferente, o sea, que construirá un discurso falso: proclamará un deber ser A, pero que en la realidad resulta $\mathrm{B}$, de lo cual no se daría por enterado.

Esta es la ley natural del derecho de Barreto, pero también, muchos años después, la tesis realista de las estructuras lógico reales (sachlogischen Strukturen) de Welzel ${ }^{104}$. Por cierto, Barreto fue más lejos que Welzel, porque su ley natural del derecho le permitió caer en la cuenta de que el poder punitivo es un factum político. Welzel se quedó a medio camino, pues llevo su tesis hasta la teoría del delito, pero no llegó a la teoría de la pena; tampoco hubiese podido hacerlo, dado que también legitimada al poder punitivo siguiendo uno de los caminos tradicionales $^{105}$.

Welzel intentaba legitimar -como tutela de un supuesto mínimo ético- al poder punitivo del tiempo de la reconstrucción alemana, provocando una peligrosa etización del derecho penal. Barreto pensaba a la intemperie, solitario en el nordeste brasileño, lo que demuestra que, a veces, el subdesarrollo tiene ventajas.

En paralelo con el derecho internacional, se verificará que los principios de libertad, igualdad, fraternidad (o solidaridad),

\footnotetext{
104 Esta apertura al realismo abría la posibilidad de utilizarlo en la forma en que lo hizo Barreto y en que lo hacemos nosotros, lo que llevó a un penalista uruguayo a sostener que facilitaba la introducción del marxismo, por mucho que esa afirmación haya constituido un verdadero disparate, aunque peligrosa en el momento en que se la formuló.

105 Welzel legitimaba el poder punitivo conforme a una supuesta ética social mínima, lo que creemos que nunca pudo ser verdad, pero después de la inflación de tipos penales de las últimas décadas, le sería hoy imposible sostener.
} 
legalidad, humanidad, dignidad de la persona humana, tutela de bienes jurídicos, culpabilidad, etc., emergentes del bloque de constitucionalidad, son violados por el poder punitivo. Sería erróneo deducir que son falsos para la ciencia jurídico penal: falsa es sólo la alucinación que pretende que en el ejercicio real del poder punitivo se los respeta escrupulosamente, frente a los datos sociales que verifican que los lesiona.

La ciencia jurídico penal debe reafirmar esos principios y verificar en qué medida en la realidad los lesiona el poder punitivo, impidiendo el paso del poder punitivo que los lesiona en mayor medida, lo que importa llevar a cabo un permanente esfuerzo para elevar su nivel o estándar de realización de los principios que nunca son realizados socialmente en forma completa, porque eso sería llegar a un estado de derecho ideal, que nunca ha existido y no sabemos si podrá existir alguna vez.

Por consiguiente, este esfuerzo siempre será un juego de pulsiones y contrapulsiones, puesto que ningún estado de derecho es conforme al ideal. Los estados reales (existentes) que se aproximan al modelo ideal de derecho siempre son una coraza que, cuanto más se acerquen al ideal, mejor encapsularán las pulsiones del estado de policía que encierra en su seno, puesto que en toda sociedad siempre existen factores de poder que pretenden imponer su voluntad arbitraria.

Este juego de pulsiones no es una dialéctica, porque no tiene síntesis. Se trata de un unfinished en que se debe hacer camino a medida que se avanza, lo que requiere prestar constante y cuidadosa atención a la permanente dinámica del poder, aspecto en el cual cobra especial importancia el reconocimiento y verificación -en cada coyuntura- de los datos sociales acerca de la mutable onticidad del poder ${ }^{106}$.

De este modo, la ciencia jurídico penal integrada con la criminología pasa a ser el apéndice indispensable del derecho

\footnotetext{
106 Según las variables del poder, lo que en un momento puede impulsar un estándar, en otro momento puede hacerlo retroceder.
} 
constitucional de cualquier estado que pretenda aproximarse al modelo de derecho, puesto que en definitiva, el poder punitivo más irracional lo debilita y su contención lo fortalece. De este modo la ciencia penal asume con plena consciencia la función que siempre cumplió cuando fue útil a la humanidad: contener las pulsiones de estado de policía o de degradación del estado y evitar el genocidio -frontal o por goteo- con el consiguiente naufragio de todos los derechos.

En síntesis: no es verdad que en nuestros días no se pueda concebir un modelo integrado de ciencia jurídico penal y criminología, sino todo lo contrario: en nuestra región, la integración es de extrema urgencia. Es muy probable que, en otras realidades y regiones del planeta, donde entre el ser y el deber ser del poder punitivo se siga manifestando una disparidad, pero no un disparate -como en la nuestra-, sus jueces puedan ejercer un discreto poder jurídico de contención conforme a elaboraciones más impermeables a los datos de realidad, pero a nosotros no nos queda otra alternativa que hacernos cargo del disparate, partiendo del reconocimiento de las deplorables condiciones del ejercicio real del poder punitivo en nuestras sociedades.

Dada esta disparatada distancia entre el ser y el deber ser en nuestra región, nuestra ciencia del derecho penal, con toda urgencia, debe dejar de legitimar -por acción o por omisión- el ejercicio más irracional e ilícito del poder punitivo que, en las últimas décadas, acentuó su carácter violento ${ }^{107}$, letal ${ }^{108}$, discriminatorio $^{109}$, misógino ${ }^{110}$ y racista $^{111}$. De lo contrario, no sólo eludiremos el deber ético de hacer el máximo de esfuerzo por

\footnotetext{
107 La tortura no ha desaparecido en Latinoamérica y menos aún todas las formas de maltrato y detenciones arbitrarias.

108 Las ejecuciones sin proceso se registran en varios países en forma alarmante.

109 La discriminación clasista es de toda evidencia en toda la región.

110 El "machismo" sigue dominante en las fuerzas de seguridad y en algunos tribunales.

111 Basta recorrer cárceles latinoamericanas para verificar a simple vista el neto predominio de ricos en melanina y comprarlo con la pobreza de melanina en las universidades, bancos, tribunales, etc.
} 
evitar males mayores en momentos de regresión del respeto a los Derechos Humanos en nuestra región y en el mundo, sino que también corremos el riesgo de que en un futuro no lejano nos estigmaticen como Francesco Carrara lo hizo con los viejos prácticos preiluministas, cuyo saber calificó de schifosa scienza $a^{112}$.

112 Carrara aspiraba a un derecho penal como ciencia sublime, que sienta su noble misión de perfeccionar a la humanidad, y que desdeñe reconocer como hermano el arte asqueroso que en tiempos pasados se llamó derecho criminal, que consistía en enseñar los dictados positivos de legisladores autónomos y crueles, en establecer los modos de circunvenir a un acusado y las medidas para regular los tramos de cuerda y las pinzas de las tenazas (Varietà della idea fondamentale del giure punitivo (Prolusione al corso accademico dell'anno 1862-63), en Opuscoli di Diritto Criminale, Prato, 1885, vol. I, pp. 154 y ss., p. 180). La designación de schifosa scienza fue retomada por Massimo Pavarini como título de su libro, traducido al castellano como Un arte abyecto, Ensayo sobre el gobierno de la penalidad, Ad-Hoc, Buenos Aires, 2006. 